Goldschmidt 2021 Abstract

https://doi.org/10.7185/gold2021.7645

\section{From a sounding rocket towards NanoSIMS analyses - An interdisciplinary student project sending Foraminifera on a rough voyage}

SEBASTIAN VICTOR GFELLNER ${ }^{1}$, KATRIN HAETTIG ${ }^{2}$, NILS KUNST ${ }^{3}$, KAY MENKENS-SIEMERS ${ }^{3}$, JAN

BLUMENKAMP $^{3}$, NIKLAS KIPRY ${ }^{3}$, DANIEL RIPBERGER ${ }^{3}$, STEFFEN LOHMANN ${ }^{3}$, GRETA SONDEJ ${ }^{3}$, CHRISTOPH $^{2}$ KULMANN $^{3}$, SCARLETT GAC CÁCERES ${ }^{3}$, DIREN SENGER $^{3}$, CLAUDIA SABINE BRUHN ${ }^{3,4}$ AND JOHANNA HARTMANN $^{3,5}$

${ }^{1}$ University of Bremen

${ }^{2}$ NIOZ Royal Netherlands Institute for Sea Research

${ }^{3}$ University Bremen

${ }^{4}$ Alfred Wegener Institute, Helmholtz Centre for Polar and Marine Research

${ }^{5}$ University of the Arts Bremen

Presenting Author: gfellner@uni-bremen.de

Aim of the student project "FORAminifera Rocket EXperiment" (FORAREX) was to test how cultivation of Foraminifera as new model organisms on board the ISS could be conducted. Amphistegina lobifera is a unicellular marine protist with a calcareous shell, capable of controlled biomineralization. The research idea was to design a novel experiment and a workflow within requirements of space missions to investigate the influence of microgravity on biomineralization. The scope of the project included the design and manufacturing of the components towards the implementation of a geochemical labeling approach. In March 2019, the experiment was tested onboard the sounding rocket REXUS 25 as part of the REXUS/BEXUS program.

Foraminifera were cultivated in a closed water cycle in a specially designed life-support system consisting of two units: The pressurized Late Access Module and the REXUS Module. A ground control group was cultivated under the same conditions. The illuminated active circulating water cycle includes a FlowCell (Fig. 1), where the Foraminifera were injected two days before rocket launch with about 2 min of microgravity. It consists of a camera and scientific sensors for measurements of oxygen, $\mathrm{pH}$, temperature, and ambient pressure. To be able to detect the shell growth during a long-term ISS mission, we added increased ${ }^{88} \mathrm{Sr}$ via injection into the waterflow right before the rocket start and ${ }^{86} \mathrm{Sr}$ after landing. The cultivation of Foraminifera continued for four more weeks after the rocket flight to simulate a long-term space mission. Afterwards, the calcitic shells were prepared for microstructure analyses via SEM. The chemical composition was first analyzed with SEMEDX and further with NanoSIMS to detect $\mu \mathrm{m}$ - to nm-scale resolution. We measured a profile through a chamber wall, detecting different calcite layers (Fig. 2).

The feasibility of the experiment demonstrates the potential of
Foraminifera as model organisms to study controlled biomineralization under microgravity. As single celled symbiontbearing organisms, they only need few resources in terms of nutrition and light, making them easy to cultivate in spacemissions. The successful design and rocket test of the FlowCell is a first step towards long term microgravity missions for biomineralization research with Foraminifera.
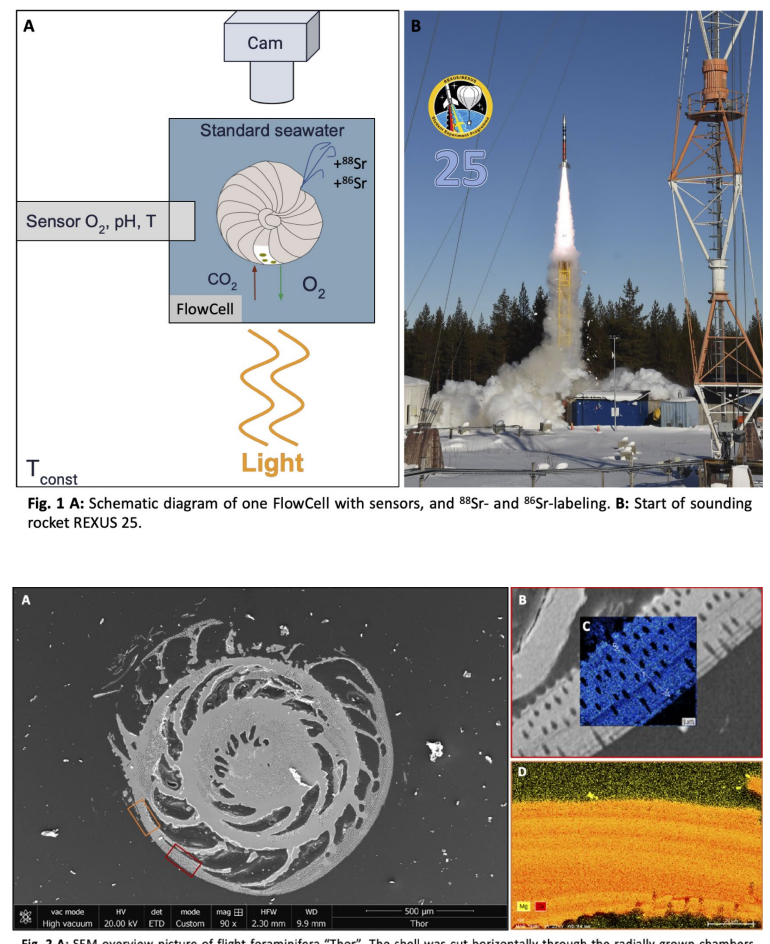
Fig. 2 A: SEM overview picture of fight foraminifiera "Thor". The shell was cut horizontally through the radially grown chambers
following the growth direction. The boxes are indicating the position of the SEM analysis, sample point Thor 2 ( lorange) and Thor 3 following the growth direction. The boxes are indicating the position of the SEM analysis, sample point Thor 2 (orangel and Thor 3
(red). B: SEM overview of Thor 3 . C: Embedded overview of the NanosiliMS measurement of elemental and isotopic compositions

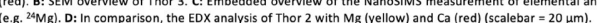

